\title{
CONSTRUCTING A DATABASE OF DEVELOPMENT APPLICATIONS CONSIDERED BY PUBLIC HEALTH UNITS IN NSW
}

Trish Mannes and Adam Capon

NSW Public Health Officer Training Program

NSW Department of Health

In NSW a formal assessment is required prior to any significant development (such as a residential development or new industry) to ensure it complies with relevant planning controls and to confirm it is environmentally and socially sustainable. ${ }^{1}$ The level of assessment required is dictated by state, regional and local planning legislation, which also outlines who is responsible for assessing and granting consent to the development, be it the local council or the NSW Minister for Planning. The NSW Environmental Planning and Assessment Act 1979 (EP\&A Act) ${ }^{1}$ provides the legislative framework to assess the environmental impact of development proposals. This article describes a survey of public health units in NSW that informed the development of a database designed to support environmental risk assessment.

In NSW an environmental impact statement (EIS) must be prepared for designated developments, that is, those that are considered to be 'high impact' or are likely to significantly affect the environment. Although non-designated developments (smaller and low impact developments) do not require an EIS, the consent authority is still required to consider the likely impacts on the environment if it grants development consent. Within the EP\&A Act, therefore, there is a formal requirement for proponents and approval authorities to consider the environmental implications of development proposals, whether an EIS is undertaken or not.

Prior to the preparation of an EIS a proponent may hold a planning focus meeting. The planning focus meeting acts as a forum for identifying key issues of concern relating to the development and allows matters that may otherwise hold up the assessment process to be dealt with early. After the planning focus meeting the proponent usually requests requirements from the Department of Planning for the preparation of the EIS; these are called Director General's Requirements. In 2005 the EP\&A Act was modified in an attempt to streamline the planning process. Although still under development, it is expected that there may be less opportunity for NSW Health to be involved in the review of development applications, increasing the impetus for NSW Health to be involved at the planning focus meeting and Director General's Requirements stage.

\section{THE ROLE OF NSW HEALTH}

Under the EP\&A Act the environment includes all aspects of the surroundings of humans, whether affecting any human as an individual or in his or her social groupings. Thus, social and health issues need to be considered in the development approval process. NSW Health does not have a statutory role under planning legislation in NSW, that is, NSW Health does not have authority to approve or reject a development. However, NSW Health, other government agencies and the general public may provide comment on any designated development application during the public exhibition period.

Development applications may be formally referred to NSW Health for advice on the potential for the development to impact on human health. NSW Health may also be invited to participate in the planning focus meeting and in contributing to the Director General's Requirements for an EIS, although participation at this stage of the process is at the discretion of the consent authority.

Public health units - the public health agencies from which health advice is generally sought-report that they experience challenges in providing comment on development applications. In general, comment on a development application must be provided within 30 days of public exhibition. This time pressure may place considerable strain on those charged with assessing the proposal, especially when highly technical processes require assessment. The development applications (and the associated EISs) are often complex, lengthy and difficult to read. However, they frequently do not provide enough information to adequately assess potential impact on human health, particularly the health promoting or limiting potential of the development. Furthermore, within the public health units there may not be adequate expertise in highly specialised areas such as risk assessment.

\section{OBJECTIVES}

We sought to compile a database of examples of environmental risk assessments undertaken by NSW Health to assist public health units in reviewing development applications. The database provides examples of comment on development applications for public health units that are reviewing similar applications. We also sought to obtain an understanding of the range of issues in development applications reviewed by NSW Health. This project is not designed to influence the way in which NSW Health becomes involved in the development assessment process.

\section{METHODS}

At the time of study, NSW Health comprised 17 area health services that were responsible for discrete geographical areas. A public health unit was located within each of these. All rural and metropolitan public health units in NSW were surveyed. We asked public health units to list all development applications that had been referred to them for comment in the previous 12 months. For each development application the public health unit was then required to outline: 
- the key health issues for consideration in the development

- whether comment was provided on the application

- whether the unit encountered any difficulties in commenting on the application

- what the outcome of their comment had been.

Three and six months after the initial mail-out, nonresponders were followed up by email and telephone.

\section{RESULTS}

Ten of the 17 public health units responded to the survey: four of the nine metropolitan and six of the eight rural public health units. Public health units reported that they had reviewed between none and thirty development applications (or related issues) in the previous 12 months. These applications had been sent to public health units by local councils and the state government planning agency. The median number reviewed was eight and the average was nine. Public health units commented on a total of 89 environmental health risk assessment issues: 34 from rural public health units and 55 from metropolitan public health units.

The types of developments reported included proposals to construct new industry; adjustment to existing industry; remediation of contaminated land; use of drinking water supplies for recreation; recreational water quality; waste treatment facilities; local environment plans; and infrastructure developments. The types of developments and issues that were considered varied considerably between units. Table 1 provides a comparison of the primary types of issues considered by rural and metropolitan area health services.

Environmental health professionals require expertise in a variety of content areas in order to examine development applications. The content areas contained within the reported development applications are summarised in Table 2 for both metropolitan and rural locations. Public health units, particularly rural public health units, are frequently required to comment on issues related to water. Other environmental health content areas frequently covered are local and state planning regulations, air quality, land contamination and waste.

Difficulties encountered by public health units in commenting on development applications include insufficient time for providing a response, difficulty finding information in the EIS, and complexity of issues in the EIS. Specific technical problems also include:

- requirements for effluent management

- local planning ordinances, for example path width, shade provisions, traffic

- waste water quality requirements and water treatment technology

- air pollution from bushfires
- effect of traffic on health

- hazardous chemicals and site contamination

- pest control.

The examples provided by public health units have been compiled into a database. Environmental health professionals in public health units will be able to use the database to obtain information on similar issues encountered by other public health units. Any public health unit will be able to access the examples in the database or contact other public health units directly for assistance and information. Table 3 provides an example of the information provided in the database.

\section{TABLE 1}

THE PRIMARY ISSUE ADDRESSED IN EACH DEVELOPMENT APPLICATION ASSESSED BY RURAL AND METROPOLITAN AREA HEALTH SERVICES IN NSW

\begin{tabular}{lccc|}
\hline & \multicolumn{3}{c|}{ Public health unit } \\
\hline $\begin{array}{l}\text { Issue or type of } \\
\text { development }\end{array}$ & $\begin{array}{c}\text { Rural } \\
\mathbf{n}\end{array}$ & $\begin{array}{c}\text { Metropolitan } \\
\mathbf{n}\end{array}$ & $\begin{array}{c}\text { Total } \\
\mathbf{n}\end{array}$ \\
\hline $\begin{array}{l}\text { Agriculture } \\
\text { Commercial and }\end{array}$ & 3 & 2 & 5 \\
industrial & 5 & 8 & 13 \\
Contaminated sites & 1 & 15 & 16 \\
Land use and local & 1 & 3 & 4 \\
environmental plans & & & \\
Mining & 0 & 1 & 1 \\
Multiple chemical & 1 & 0 & 1 \\
sensitivity & & & \\
Residential & 5 & 2 & 7 \\
Tourism (other than & 1 & 2 & 3 \\
eco) & & & 2 \\
Transport & 1 & 1 & 14 \\
Waste disposal/ & 4 & 2 & 2 \\
treatment & & 0 & 3 \\
Waste to energy & 0 & 4 & 11 \\
Water: drinking and & 3 & 2 & 3 \\
recreational & & & \\
Wastewater re-use & 7 & & \\
Other & 1 & & \\
\hline
\end{tabular}

\section{TABLE 2}

CONTENT AREAS CONSIDERED WITHIN THE REPORTED DEVELOPMENT APPLICATIONS FOR METROPOLITAN AND RURAL AREAS

\begin{tabular}{|lccc|}
\hline & $\begin{array}{c}\text { Metropolitan } \\
\text { areas } \\
\mathbf{n}\end{array}$ & $\begin{array}{c}\text { Rural } \\
\text { areas } \\
\mathbf{n}\end{array}$ & Total \\
Content considered & $\mathbf{5 5}$ & $\mathbf{3 4}$ & $\mathbf{n}$ \\
\hline Air quality & 14 & 8 & 22 \\
Water quality & 14 & 27 & 41 \\
Land contamination or & 14 & 2 & 16 \\
chemicals & & 5 & \\
Noise & 1 & 14 & 21 \\
Local/state planning & 7 & 9 & 15 \\
Waste & 6 & 9 & 10 \\
Arbovirus & 1 & 4 & 4 \\
Food & 0 & & \\
\hline Note: $\quad$ More than one content area may be assigned to a & \\
\multicolumn{2}{r}{ single development application. } \\
\hline
\end{tabular}


TABLE 3

\section{EXTRACT FROM THE ENVIRONMENTAL RISK ASSESSMENTS DATABASE, DEMONSTRATING FIELDS}

\begin{tabular}{|c|c|c|c|c|}
\hline Title & Issue & Classification & $\begin{array}{l}\text { Public health } \\
\text { unit }\end{array}$ & Action \\
\hline Rural town livestock exchange & $\begin{array}{l}\text { Emergency management plan } \\
\text { Odour } \\
\text { Q fever (vaccinations) } \\
\text { Treatment and reuse of waste } \\
\text { Food outlets } \\
\text { Pest control }\end{array}$ & Agriculture & Rural & $\begin{array}{l}\text { Comment provided } \\
\text { Approval pending }\end{array}$ \\
\hline Site management plan for contaminated site & $\begin{array}{l}\text { Odour } \\
\text { Noise } \\
\text { Contaminated dust exposure } \\
\text { Warning signs } \\
\text { Protective equipment for workers }\end{array}$ & Contaminated site & City & $\begin{array}{l}\text { Comment provided } \\
\text { Outcome unknown }\end{array}$ \\
\hline
\end{tabular}

\section{DISCUSSION}

This project provides a nucleus for an expanding database of environmental risk assessment issues. The database forms a resource for the NSW public health units that may facilitate communication and collaboration on areas of mutual interest; however, the utility of the database should be evaluated.

Only 10 of the 17 area health services responded to the survey, thus generalisations about results are limited. Also, the examples obtained from the survey are unlikely to be a complete list of issues that a public health unit has been asked to comment on. There is considerable variability between public health units in relation to the types of issues examined. This variability may be due to differences in risk assessment issues in different public health unit regions (such as urban and rural, industrial and agricultural), or the limited survey period (only one year of risk assessments). It is also possible that issues referred to public health units from local government are driven by historical relationships and interest and enthusiasm within public health units and local government about particular issues. However, the survey has provided a useful overview of the types of issues that some public health units are receiving and providing population health advice on. This understanding has implications for the training and professional development of environmental health professionals in public health units. This project confirms anecdotal reports of difficulties experienced by public health units in meeting deadlines for comment and examining complex risk assessment issues.

This survey shows that the majority of development applications commented on by NSW Health concern health protection, such as air and water quality, rather than health promotion, such as environmental constraints to physical activity. This may indicate that consent authorities do not recognise the potential relevance of urban development to health, or have been unable to engage NSW Health about these issues in the past. Greater involvement by health promotion practitioners may provide a more comprehensive response to proposed developments with an appropriate emphasis on the potential 'positive' health benefits of proposals.

While NSW Health does not have a statutory role, comment on development applications provides the potential to intervene in the planning process to protect and promote human health, rather than simply react to minimise harm. The greatest potential for input into a development comes with early involvement in the planning process, even before the consent authority receives the application.

This database has been designed to provide support to public health units so that these measures may be undertaken more effectively. However, there is a need for additional analysis of the process of involvement of NSW Health in development assessments such that the potential of NSW Health to engage effectively with the planning process is maximised.

\section{ACKNOWLEDGEMENTS}

This work was carried out with the assistance of the Environmental Health Branch of the NSW Department of Health. The authors wish to thank the Directors of, and environmental health staff in, public health units for completing the survey and providing sample development applications for the database. The authors also wish to acknowledge the assistance of Glenis Lloyd and Vicky Sheppeard of the NSW Department of Health's Environmental Health Branch in preparing the manuscript for submission.

\section{REFERENCE}

1. Environmental Planning and Assessment Act of 1979. No 203. Available from www.legislation.nsw.gov.au. Accessed November 2005. 욤 